\title{
In-vivo Inhibition of Glutathione S-Transferase P1 by Bovine Lactoferricin in Swiss Albino Tumor Bearing Mice
}

\author{
Amir Riyaz Khan, Pankaj Taneja* \\ Department of Biotechnology; School of Engineering and Technology, Sharda University Greater Noida; U.P. India.
}

\section{ARTICLE INFO}

Article history:

Received on: 23/09/2016

Revised on: 28/10/2016

Accepted on: 10/11/2016

Available online: 29/11/2016

Key words:

In vivo, GSTP1, Lfcin B, Tumor, Skin Cancer, Enzyme Inhibition.

\begin{abstract}
Many cancers overexpress GSTP1 which contributes to multidrug resistance via conjugation of antineoplastic drugs. The aim of this paper is to investigate the in-vivo interaction of GSTP1 and Lfcin B in Swiss albino female mice induced with skin cancer using 7, 12 dimethylbenz (a) anthracene. Group B and C received topical application of DMBA, whereas group C was subcutaneously injected with $200 \mu \mathrm{l}(20 \mu \mathrm{g} / \mu \mathrm{l}) \mathrm{Lfcin}$ B while keeping group A as a control. The activity of GSTP1 in all the groups was then estimated spectrophotometrically at $340 \mathrm{~nm}$ by taking the increase in absorbance of GS-DNB conjugate. Administration of $200 \mu \mathrm{l}(20 \mu \mathrm{g} / \mu \mathrm{l}) \mathrm{Lfcin}$ B three times per week was found to significantly $(\mathrm{p}<0.01)$ inhibit GSTP1. GSTP1 was observed to be overexpressed in group B (treated with DMBA only as skin carcinogen). Significant differences $(\mathrm{P}<0.01)$ were observed between group $\mathrm{A}$ (control) and $\mathrm{C}$ (DMBA+ Lfcin B group) indicating in vivo inhibition of GSTP1 by Lfcin B. We concluded that Lfcin B competitively inhibits GSTP1 in-vivo. Accordingly, Lfcin B may emerge as a suitable pharmacological agent that can selectively target GSTP1 thereby inducing cancer cells to apoptosis.
\end{abstract}

\section{INTRODUCTION}

Glutathione S-transferases (GST) consists of a family of enzymes with various functions i.e. xenobiotic detoxification. GSTP1 which comes in the Pi class of GST is found to be overexpressed as well as contributes to multidrug resistance by the conjugation of therapeutic drugs. Furthermore, GSTP1 have antiapoptotic properties as it interacts with JNKs (c-jun NH2terminal kinase) which is a key regulator of programmed cell death. This marks GSTP1 a promising chemotherapeutic agent. (Federici et al; 2009). Glutathione S-transferase pi (GSTP1) is an essential enzyme which is categorized in Glutathione S-Transferase family. Their main function is to perform

\footnotetext{
* Corresponding Author

Pankaj Taneja, Department of Biotechnology; School of Engineering and Technology, Sharda University Greater Noida; U.P. India 201306 Email: pankajtnj @yahoo.com
}

detoxification reaction of xenobiotic compounds thus it inactivates various electrophilic carcinogens through conjugating glutathione reduced (Toffoli et al; 1992; Jeronimo et al; 2001). GSTP1 takes part in various detoxification reactions by the catalysis of conjugation of many electrophilic and hydrophobic compounds with glutathione reduced (Jeronimo et al; 2001). GSTP1 is found to be overexpressed in variety of cancers such as breast, bladder, pancreas, colon, stomach, lung, neck, head, cervix, ovary and various soft tissues such as sarcoma, carcinoma, of testicules, glioma and meningioma (Niitsu et al; 1989; Randall et al; 1990; Kantor et al; 1991; Satta et al; 1992; Green et al. 1993; Inoue et al; 1995; Bentz et al; 2000; Trachte et al; 2002; Simic et al; 2005; Arai et al; 2006). The function of GSTP1 is to metabolize various xenobiotics and to involve with susceptibility to cancer and other diseases. Various reports show that overexpression of GSTP1 is linked to acquired resistance to various chemotherapeutic drugs (Wang et al; 2008). 
GSTP1 has a variety of substrate including endogenous compounds as well as antineoplastic drugs such as cisplatin, chlorambucil interact with difference and control the signaling pathways such as proliferation and apoptosis and differentiation. GSTP1 interact and inhibit c-Jun-N-terminal kinase (JNK), a transcription factor which is having a specific role in apoptosis and cell signaling. Protein kinase $\mathrm{C}(\mathrm{PKC})$ and epidermal growth receptor (EGFR) phosphorylates GSTP1 which results in increased catalytic activity of the GSTP1 and subsequently responsible for drug resistance (Rabindran et al; 2004; Singh et al; 2010; Okamura et al; 2009). Recently we have demonstrated the interaction of Lactoferricin B (Lfcin B) with GSTP1 from human placental and breast cancer cell line MDA-MB-231. The findings suggest that Lfcin B inhibits the GSTP1 activity in human placental and MDA-MB-231 breast cancer cell lines, which may induce synergistic effects when used in combination with antineoplastic drugs that are substrates of the GSTP1 enzyme (Khan and Taneja, 2015).

In this current research, we have investigated the in vivo interaction of GSTP1 and Lfcin B in Swiss albino female mice induced with skin cancer using 7, 12 dimethylbenz (a) anthracene.

\section{MATERIALS AND METHODS}

\section{Animals}

Female Swiss Albino mice 5-8 weeks old, weighing 20$35 \mathrm{~g}$ were purchased from Luvas, Haryana, India. The animals were maintained in the Central Animal House, Sharda University. The animals were housed in polypropylene cages and provided standard pellet diet and water ad libitum and maintained under controlled conditions of temperature and humidity, with a $12 \mathrm{~h}$ light/ dark cycle.

\section{Chemicals}

Reduced glutathione (GSH) was purchased from calbiochem (India), 1-chlro-2, 4-dinitro benzene (CDNB) were procured from Sigma Aldrich (India). Lfcin B (with sequence RRWEWRMKKLG), was designed at Bioconcept Lab Pvt Ltd. IMT Manesar, Gurgaon, Haryana, India.

\section{Experimental protocol and treatment}

A total number of 30 animals were divided equally into 3 groups i.e. A, B and C. Each group consists of 10 animals. Group A was used as a control and was given $200 \mu$ l of acetone as a topical application on shaved skin. Group B and C animals were applied with $200 \mu \mathrm{l}$ of DMBA $(0.025 \mu \mathrm{g} / \mu \mathrm{l})$ per animal three times per week as a topical application on the shaved skin. Group $C$ animals were also injected subcutaneously with $200 \mu$ l of Lfcin B $(20 \mu \mathrm{g} / \mu \mathrm{l})$ after a gap of 30 minutes after topical application of DMBA.

Group A (10 animals) (Control) - Treated with acetone only Group B (10 animals) - Treated with DMBA alone.
Group C (10 animals) -Treated with DMBA+ Lfcin B

\section{Preparation of Tissue Homogenate}

Liver and kidneys were carefully excised from the animals, washed in a phosphate buffer saline (PBS) and weighed. A homogenate of the tissues was made in $100 \mathrm{mM}$ potassium phosphate buffer ( $\mathrm{pH}$ 6.8) and was used for the estimation of glutathione S-transferase P1 (GSTP1).

\section{Determination of enzymatic activity}

The activity of GST enzyme was estimated by the protocol described by Habig et. al; 1974. The reaction mixture consists of $1000 \mu \mathrm{l}$ of $100 \mathrm{mM}$ potassium phosphate buffer ( $\mathrm{pH} 6.8$ ) , $100 \mu \mathrm{l}$ of 1-chloro-2, 4-dinitrobenzene (CDNB), $100 \mu \mathrm{l}$ of homogenate and $1700 \mu \mathrm{l}$ of D.W. was incubated at $37^{\circ} \mathrm{C}$ for $5 \mathrm{~min}$. The reaction was then started by the addition of $1000 \mu \mathrm{l}$ of glutathione. The increase in absorbance was followed for 3 minutes at $340 \mathrm{~nm}$.

\section{Total protein}

Total protein concentration was calculated according to the protocol described by Lowry et al; 1951 using Folin-Ciocalteu reagent (FCR). Bovine serum albumin was used as a standard. Absorbance was recorded at $660 \mathrm{~nm}$ and the amount of protein was calculated using the standard curve and expressed as $\mu \mathrm{g} / \mathrm{ml}$.

\section{Statistical Analysis}

The investigational results acquired are expressed as mean \pm standard deviation (SD). The data was imperiled to oneway analysis of variance (ANOVA) and differences between samples were determined by Tukey multiple comparison tests using the SPSS 22. The level of significance was set at $\mathrm{p}<0.01$.

\section{RESULTS AND DISCUSSION}

The outcomes of the study show that Lfcin B possesses chemoprotective effect. Administration of DMBA has produced $100 \%$ tumor incidence in Group B (DMBA alone treated group) at the end of the $16^{\text {th }}$ week while only $20 \%$ developed tumors in the Group C (DMBA+ Lfcin B) treated group. The size of the tumors in the group $\mathrm{C}$ was found to be significantly $(\mathrm{P}<0.01)$ reduced than those treated by Group B. The tumor volume of DMBA alone was found to significantly $(\mathrm{P}<0.01)$ higher than those group $\mathrm{C}$. The tumor burden and total number of tumor were also found to be higher in group B in comparison to group C. (Table 1). The results of the analysis of GSTP1 are presented in table 2. Lowest level of GSTP1 was observed in group C (DMBA + Lfcin B treated group). A significant difference was observed between all the group at $\mathrm{P}<0.01$. This is due to the fact that the GSTP1 is inhibited in vivo by Lfcin B in group B and C (DMBA alone and DMBA + Lfcin B treated group respectively) and GSTP1 was overexpressed in the group B (treated with DMBA only). In the liver of the experimental mice, GSTP1 in group $\mathrm{C}$ was found to be lower than the other groups (group A and B) presented in table 2. 
Table 1: The impact of Lfcin B on various tumor parameters in DMBA treated mice.

\begin{tabular}{|c|c|c|c|c|c|}
\hline Group & Tumor Incidence & Tumor size $(\mathrm{cm})$ & Tumor volume $\left(\mathrm{cm}^{3)}\right.$ & Tumor burden $\left(\mathrm{cm}^{3)}\right.$ & Total number of tumors \\
\hline Group B & $100 \%(10 / 10)$ & $0.60 \pm 0$ & $0.36 \pm 0.40^{\mathrm{a}}$ & $3.43 \pm 4.16^{\mathrm{a}}$ & $7.70 \pm 3.89^{\mathrm{a}}$ \\
\hline Group C & $20 \%(2 / 10)$ & $0.12 \pm 0.15^{\mathrm{b}}$ & $0.004 \pm 0.005^{\mathrm{b}}$ & $0.005 \pm 0.007^{\mathrm{b}}$ & $0.50 \pm 0.71^{\mathrm{b}}$ \\
\hline
\end{tabular}

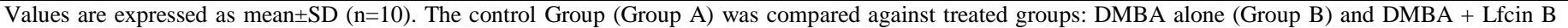
(Group C) "a" and "b" are the superscript denoting statistical significance.

Table 2: Hepatic and Renal GSTP1 and total protein values after Lfcin B inhibition.

\begin{tabular}{|c|c|c|c|}
\hline & Group A $(\mu \mathrm{mol} / \mathrm{ml} / \mathrm{min})$ & Group B ( $\mu \mathrm{mol} / \mathrm{ml} / \mathrm{min})$ & Group C ( $\mu \mathrm{mol} / \mathrm{ml} / \mathrm{min})$ \\
\hline Hepatic GSTP1 inhibition by Lfcin B & $174.69 \pm 2.19^{*}$ & $207.95 \pm 1.48 * *$ & $135.17 \pm 2.61 * * *$ \\
\hline \multirow[t]{2}{*}{ Renal GSTP1 inhibition by Lfcin B } & $215.68 \pm 1.40^{*}$ & $352.28 \pm 1.46^{* *}$ & $141.65 \pm 1.68 * * *$ \\
\hline & Group A (g/ml) & Group B (g/ml) & Group C (g/ml) \\
\hline Total hepatic protein content. & $4.65^{*}$ & $4.38 * * *$ & $4.59 * * *$ \\
\hline Total renal protein content. & $3.37 *$ & $2.97 * *$ & $3.33 * * *$ \\
\hline
\end{tabular}

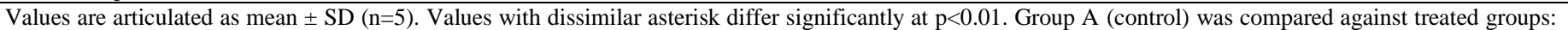
Group B (DMBA alone) and Group C (DMBA+ Lfcin B)

Normal expression was seen in the control group (group A) whereas high expression was observed in the group B (DMBA alone). A similar result was observed in the kidneys of experimental animals. In the kidneys, overexpression of GSTP1 was observed in group B (DMBA alone treated group) whereas lowest expression of GSTP1 was in group C (DMBA + Lfcin B treated group). A significant difference was observed between group $\mathrm{A}, \mathrm{B}$, and $\mathrm{C}(\mathrm{P}<0.01)$. Administration of $200 \mu \mathrm{l}(25 \mu \mathrm{g} / \mu \mathrm{l})$ Lfcin B three times per week was found to significantly inhibit GSTP1 in both liver and kidneys of group $\mathrm{C}$ indicating the in vivo inhibition of GSTP1 by Lfcin B.

Estimation of protein content has revealed that total protein content in group B (DMBA alone) treated animals was found to be depleted compared to other groups as presented in table 2. This indicated the toxicity of DMBA to the genetic materials thereby disrupting the protein synthesis in both kidneys and liver. A significant difference was observed between group A, $\mathrm{B}$, and $\mathrm{C}$ and topical application of $200 \mu \mathrm{l}$ of DMBA at concentration of $0.025 \mu \mathrm{g} / \mu \mathrm{l}$ per animal for three weeks was found to significantly inhibits protein synthesis in both group B and $\mathrm{C}$. Compared to group $\mathrm{B}$, group $\mathrm{C}$ was to be closer in the protein contents than the group B. This also indicates the reversal effect of $200 \mu \mathrm{l}(25 \mu \mathrm{g} / \mu \mathrm{l})$ of Lfcin B as a result of the assault induced by the topical application of DMBA. In both the liver and kidneys protein was found to be depleted following topical application of DMBA probably due to stress, however, subcutaneous injection of Lfcin B significantly restored by the protein contents. It was described that the carcinogen, DMBA upsets intracellular calcium balance thereby damaging endoplasmic reticulum which results in depletion of protein (Sharma et al; 2010).

A similar result to this research in our previous finding was reported in vitro by observing the interaction of Lfcin B with human placental GSTP1 and breast adenocarcinoma MD-MB-231 cell line. The result of the research suggested that Lfcin B is a competitive inhibitor with respect to GSH binding site (G-site) and noncompetitive inhibitor with respect to the hydrophobic substrate unit (H-site) of the human placental GSTP1 enzyme. Following the observation that GSTP1 was overexpressed in most cancer cells (Khan and Taneja, 2015), inhibitors of GSTP1 could play important role in suppression of GSTP1 activity thereby overcoming and sensitizing the cancers cells to a chemotherapeutic agent (Tsuchida and Sato, 1992). Lfcin B was proposed to modulate the activity of GSTP1 by three different ways (Khan and Taneja, 2015) i.e. by directly interacting with GSTP1 and inhibiting its active site, by inhibiting GSTP1 binding with JNK and c-Jun or by inhibiting GSTP1 complex formation with TRAF2 (TNF receptor-associated factor 2) and ASK (apoptosis signalregulating kinase). Chemotherapeutic sensitization can be initiated following JNK activation and phosphorylation of C-jun as a result of ROS and other stress responses (Khan and Taneja, 2015). Topical application of DMBA induced oxidative stress to genetic materials thereby initiating the process of carcinogenesis. Accordingly, JNK associated with stress response, apoptosis, inflammation, cellular differentiated and proliferations (Karin and Gallagher, 2005). Peptides have become apparent as assuring remedial agents in the cure of cancer, diabetes, and cardiovascular diseases, and presentation of peptides in a variety of other therapeutic sections is growing swiftly (Thundimadadathil, 2012). In spite of the progress that was recorded in the development of anticancer drugs, challenges continue to rise particularly due to the resistance of the cancer chemotherapies and low sensitivity of the commercially available anticancer drugs (Loza et al ; 2013). Peptides for eg. Lfcin B which are host resistance peptides also acting as effector molecules of innate immunity as well may signify an innovative approach for the development of substitute anticancer drug molecules. Cationic peptides are unaffected by multidrug resistance mechanisms (Riedl et al; 2011; Fadnes et al; 2011) and have been revealed to provoke a defending immune response in contrast to solid tumors, thus making them noteworthy candidates for emerging novel prime substitutes for anticancer treatment. Further studies will be required to elucidate the more clinical significance of the above findings.

\section{CONCLUSION}

Subcutaneous administration of $200 \mu$ l of Lfcin B inhibits GSTP1 in both liver and kidneys of DMBA induced tumor-bearing 
mice. Accordingly, Lfcin B may emerge as a suitable pharmacological agent that can selectively target GSTP1 thereby inducing cancer cells to apoptosis. Further studies will be required to elucidate its mechanism of chemoprevention.

Financial support and sponsorship: Nil.

Conflict of Interests: There are no conflicts of interest.

\section{REFERENCES}

Arai T., Miyoshi Y., Kim SJ., Taguchi T., Tamaki Y., Noguchi S. Association of GSTP1 CpG islands hypermethylation with poor prognosis in human breast cancers. Breast Cancer Res Treat, 2006; 100:169-176

Bentz BG., Haines GK $3^{\text {rd }}$, Radosevich JA. Glutathione Stransferase pi in squamous cell carcinoma of the head and neck. Laryngoscope, 2000; 110:1642-1647.

Fadnes B., Uhlin-Hansen L., Lindin I., Rekdal Ø. Small lytic peptides escape the inhibitory effect of heparan sulfate on the surface of cancer cells. BMC Cancer, 2011; 11:116.

Federici L., Lo Sterzo C., Pezzola S., Di Matteo A., Scaloni F., Federici G., et al. Structural basis for the binding of the anticancer compound 6-(7-nitro-2,1,3-benzoxadiazol-4-ylthio) hexanol to human glutathione S-transferases. Cancer Res, 2009; 69: 8025-8034.

Green JA., Robertson LJ., Clark AH. Glutathione S-transferase expression in benign and malignant ovarian tumors. Br J Cancer, 1993; 68: 235-239.

Habig WH., Pabst MJ., Jakoby WB. Glutathione-Stransferases: the first enzymatic step in mercapturic acid formation. J. Biol Chem, 1974; 249: 7130-7139.

Inoue T., Ishida T., Sugio K., Maehara Y., Sugimachi K. Glutathione $\mathrm{S}$ transferase $\mathrm{Pi}$ is a powerful indicator in chemotherapy of human lung squamous-cell carcinoma. Respiration, 1995; 62: 223-227.

Jeronimo C., Usadel H., Henrique R., Oliveira J., Lopes C., Nelson WG. Quantitation of GSTP1 methylation in non-neoplastic prostatic tissue and organ-confined prostate adenocarcinoma. J Natl Cancer Inst, 2001; 93: 1747-1752.

Kantor RR., Giardina SL., Bartolazzi A., Townsend AJ., Myers CE., Cowan KH. Monoclonal antibodies to glutathione S-transferase piimmunohistochemical analysis of human tissues and cancers. Int J Cancer, 1991; 47: 193-201.

Khan AR., Taneja P. Cationic Peptide Lactoferricin B inhibits glutathione S-transferase P1 from human placenta and breast cancer cell line MDA-MB-231 preventing anticancer drug metabolism. Int J Pharm Pharm Sci, 2015; 7: 238-241.

Lowry OH., Rosebrough NJ., Farr AL., Randall RS. Estimation of protein by using Folin-phenol reagent. J Biol Chem, 1951; 193: 267275 .

Lozza C., Navarro-Teulon I., Pèlegrin A., Pouget JP., Vivès E. Peptides in receptor-mediated radiotherapy: from design to the clinical application in cancers. Front Oncol, 2013; 3: 247.

Niitsu Y., Takahashi Y., Saito T., Hirata Y., Arisato N., Maruyama H., Kohgo Y., Listowsky I. Serum glutathione-S-transferase-pi as a tumor marker for gastrointestinal malignancies. Cancer, 1989; 63: 317-323.
Okamura T., Singh S., Buolamwini J. Tyrosine phosphorylation of the human glutathione S-Transferase P1 by epidermal growth factor receptor. J Biol Chem, 2009; 284:16979-169789.

Rabindran SK., Discafani CM., Rosfjord EC., Baxter M., Floyd MB., Golas J, et al. Antitumor activity of HKI-272, an orally active, irreversible inhibitor of the HER-2 tyrosine kinase. Cancer Res, 2004; 64: 3958-3965.

Randall BJ., Angus B., Akiba R., Hall A., Cattan AR., Proctor SJ et al. Glutathione S-transferase (placental) as a marker of transformation in the human cervix uteri: an immunohistochemical study. Br J Cancer, 1990; 62: 614

Riedl S., Zweytick D., Lohner K. Membrane-active host defense peptides- Challenges and perspectives for the development of novel anticancer drugs. Chem Phys Lipids, 2011; 164: 766-781.

Satta T., Isobe K., Yamauchi M., Nakashima I., Takagi H. Expression of MDR1 and glutathione $\mathrm{S}$ transferase-pi genes and chemosensitivities in human gastrointestinal cancer. Cancer, 1992; 69: 941-946.

Sharma V., Sharma A., Kansal L. The effect of oral administration of Allium sativum extracts on lead nitrate induced toxicity in male mice. Food and Chemical Toxicol, 2010; 48: 928-936.

Simic T., Mimic-Oka J., Savic-Radojevic A., Opacic M., Pljesa M., Dragicevic D. Glutathione S-transferase T1-1 activity upregulated in transitional cell carcinoma of urinary bladder. Urology, 2005; 65:10351040 .

Singh S., Omkura T., Ali-Osman F. Serine phosphorylation of glutathione S-transferase P1 (GSTP1) by PKC $\alpha$ enhances GSTP1dependent cisplatin metabolism and resistance in human glioma cells. Biochem Pharmacol, 2010: 80: 1343-1355.

Toffoli G., Frustaci S., Tumiotto L., Talamini R., Gherlinzoni F., Picci P, et al. Expression of MDR1 and GST-pi in human soft tissue sarcomas: relation to drug resistance and biological aggressiveness. Ann Oncol,1992; 3: 09-63.

Trachte AL., Suthers SE., Lerner MR., Hanas JS., Jupe ER., Sienko AE. Increased expression of alpha-1-antitrypsin, glutathione $S$ transferase pi and vascular endothelial growth factor in human pancreatic adenocarcinoma. Am J Surg, 2002; 184:647-648.

Tsuchida S., Sato K. Glutathione transferases and cancer. Crit Rev Biochem Mol Biol,1992; 27: 337-384.

Thundimadathil J. Cancer treatment using peptides: current therapies and future prospects. J Amino Acids, 2012; 2012: 1-13.

Wang W., Xia CQ., Liu N., Gan L., Zheng J. Mechanistic study of potentiation of chemotherapy by a haloenol lactone derivative in vitro. Cancer Chemotherapy and Pharmacology, 2008; 62:117-122.

\section{How to cite this article:}

Khan AR, Taneja P. In-vivo Inhibition of Glutathione S-Transferase P1 By Bovine Lactoferricin in Swiss Albino Tumor Bearing Mice. J App Pharm Sci, 2016; 6 (11): 210-213. 